\title{
Sobre dos tratamientos aristotélicos de los argumentos aparentes: el caso de la Composición y la División
}

\author{
Gabriela RossI \\ Universidad Católica de Chile \\ rossigabriela@gmail.com
}

\begin{abstract}
Resumen: El presente trabajo se ocupa del tratamiento aristotélico de dos argumentos aparentes o falacias: la Composición y la División. En primer lugar, se analiza el modo en que Aristóteles presenta estos argumentos en las Refutaciones Sofísticas $(S E)$ y, en segundo lugar, se estudia la presentación de Retórica (Rh.) II, 24. Esto permite ver que lo que en uno y otro escrito se llama Composición y División está referido, en realidad, a argumentos aparentes con una estructura totalmente diferente. Así, el caso de la Composición y la División muestra de manera ejemplar hasta qué punto el tratamiento de las falacias en $R h$., II, 24 no es una mera repetición de lo estudiado en $S E$, sino que implica una fuerte innovación que responde, en parte, a las características del objeto de la argumentación retórica.
\end{abstract}

\section{On the Aristotelian treatment of two deceitful arguments: Composition and Division}

\begin{abstract}
This paper deals with the Aristotelian treatment of two fallacies or deceitful arguments: Composition and Division. First I examine the way in which Aristotle presents these arguments in the Sophistic Refutations (SE), and secondly, I study the presentation of Rhetoric (Rh.), II, 24. This analysis makes clear that in each writing, "Composition" and "Division" are actually referred to arguments with a completely different structure. To this extent, Composition and Division are presented as a particularly clear example of the fact that the treatment of fallacies in $R h$. II, 24 is not a mere repetition of what had been studied in $S E$, but implies a strong innovation, partly dependent on the particular subject matter of rhetorical argumentation.
\end{abstract}

Palabras ClaVe: Falacias, Retórica, Dialéctica, Argumentación.

KEYWORDS: Fallacies, Rhetoric, Dialectic, Argumentation.

RECEPCIÓN: 19 DE OCTUBRE DE 2010.

ACEPTACIÓN: 30 de marzo de 2011. 



\section{Sobre dos tratamientos aristotélicos de los argumentos aparentes: el caso de la Composición y la División}

El estudio de los argumentos aparentes o falacias ha merecido la preocupación de una numerosa serie de filósofos, quienes, durante el curso de la historia de la filosofía, de Aristóteles en adelante, se han ocupado del tema con diverso éxito en cuanto a la importancia y originalidad de sus respectivos aportes. ${ }^{1}$ Se trata de identificar, enumerar y, en lo posible, clasificar, bajo un número finito de rótulos que configuren una tipología más o menos sistemática, la multiplicidad de errores que pueden encontrarse en la práctica argumentativa, lo cual se lleva a cabo (a mi entender en su mismo origen con Aristóteles) con un propósito menos teórico que práctico: se procura principalmente sentar condiciones para desarrollar la capacidad de identificar estos errores en la práctica argumentativa concreta, con el fin de evitarlos en la propia tarea reflexiva, o bien de denunciarlos y neutralizar su eficacia cuando son cometidos intencionalmente por otros copartícipes en la argumentación. ${ }^{2}$ Este fin, evidentemente, resulta tanto más urgente cuanto más significativo sea el papel otorgado a la práctica argumentativa (tanto en el ámbito privado como en el público) como medio

\footnotetext{
${ }^{1}$ No incluyo antes a Platón por considerar que no se encuentra en sus diálogos un estudio sobre las falacias (probablemente esto se deba a la elección del drama como forma literaria para sus escritos, o la mayor parte de los mismos). Con esto no pretendo sugerir la idea de que Platón no fuera capaz de discernir estos errores o fuera insensible frente al fenómeno de la argumentación aparente, tesis contra la que aporta argumentos convincentes R. Sprague, 1962, p. xi, 7 nota 5 y p. 80 ss.

${ }^{2}$ Otro tipo de condiciones categorialmente diferentes son las que se refieren a la habilidad de aplicar estos conocimientos en la práctica, i. e. en las situaciones argumentativas particulares y concretas en las que podemos vernos involucrados. Este tipo de requisitos no podría ser satisfecho mediante un tratado (más allá de que su propósito sea teórico o
} 
legítimo de dirimir cuestiones, tomar decisiones, investigar y resolver desacuerdos teóricos o prácticos. ${ }^{3}$ El estudio y detección de las falacias, con todo, suele tener consecuencias también desde el punto de vista teórico como impulso para el desarrollo de nuevas doctrinas filosóficas a partir de la rectificación de los errores argumentativos cometidos por los anteriores filósofos. ${ }^{4}$ Incluso, los problemas suscitados alrededor de las teorías que intentan formularse para abordar las falacias como objeto de estudio también han tenido un papel no menor como motor del desarrollo de la propia teoría de la argumentación contemporánea, en especial la llamada "lógica informal". 5 Un rasgo compartido por las líneas actuales de la lógica informal, en cuanto conciben a la argumentación como un fenómeno necesariamente dialógico, es precisamente su -en muchos casos autoproclamado- linaje aristotélico, retomando una tradición de teoría de la argumentación dialógica que se remonta a los Tópicos, cuyo último libro, Refutaciones Sofísticas (SE), ${ }^{6}$ se encuentra dedicado al estudio de lo

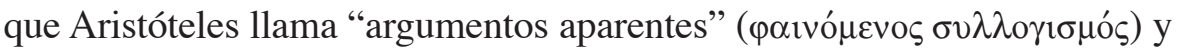
que nosotros hoy día llamaríamos "falacias".

Además del estudio de las $S E$, hay otros dos textos en los que Aristóteles discute el problema de los argumentos aparentes, a saber: Analíticos Primeros, II, 16-21 y Retórica, II, 24. En este trabajo dejaré de lado el planteamiento de Analíticos Primeros y me concentraré, en cambio, en los de $S E$ y de $R h$. . II, 24.

En las $S E$, Aristóteles estudia primariamente los argumentos aparentes que pueden darse en el contexto del intercambio dialéctico al que se

práctico) por la sencilla razón de que no se trata de un saber que se pueda obtener solamente a través del estudio de contenidos proposicionales como por ejemplo el estudio de reglas, sino de una habilidad que debe desarrollarse a partir de la práctica y que consiste, más bien, en poder aplicar esas reglas.

${ }^{3}$ A pesar de la voluntad de construir tipologías lo más acabadas posible, es preciso reconocer que este fin difícilmente podría considerarse alguna vez alcanzado. En este sentido, H. Joseph, a propósito de la posibilidad de llegar a buen término al emprender una tarea tal, a comienzos del siglo pasado, afirma: "Truth may have its norms, but error is infinite in its aberrations [...]" (Joseph, 1916, p. 569).

${ }^{4}$ Cf. J. Brunschwig, 1995, p. II.

${ }^{5}$ El punto de partida comúnmente reconocido es el trabajo de C. L. Hamblin, 1970. Entre los representantes de la llamada lógica informal puede mencionarse principalmente a F. Van Eemeren y R. Grootendorst, D. Walton, M. Finocchiaro, A. Blair y R. Johnson.

${ }^{6}$ Para todos los textos clásicos se adoptan las abreviaturas de LSJ. 
refieren los Top. Se trata de un diálogo reglado, en el cual se enfrentan dos interlocutores, uno de los cuales (quien pregunta) procura refutar al otro (quien responde). ${ }^{7}$ A pesar de ello, vale aclarar que, en el contexto de $S E$, se considera también la posibilidad de que estos argumentos aparentes no ocurran en un diálogo, sino que el filósofo se tope con ellos en la investigación realizada de modo solitario (175a9-12; cf. 169a40-169b1); de ahí que $S E$ tengan también una utilidad para la filosofía. ${ }^{8}$ Como quiera que sea, esto abre la posibilidad de entender los argumentos aparentes estudiados en este escrito no sólo como engaños intencionales por parte del erístico o del sofista en un diálogo real frente a un oponente, sino incluso como errores involuntarios que es posible que un filósofo cometa en la reflexión solitaria, una tarea que, además, en la práctica aristotélica, incluye en no poca medida la investigación y el trabajo sobre material escrito. ${ }^{9}$ En este sentido, son significativas las alusiones en $S E$ a argumentos que han sido sentados por escrito

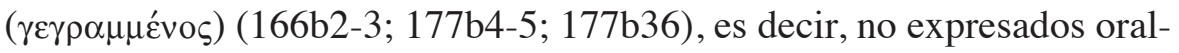
mente $(\lambda \varepsilon \gamma o ́ \mu \varepsilon v o \varsigma)$ como ocurriría en un diálogo. ${ }^{10}$ Estas alusiones, si bien no son abundantes, aparecen en relación con el argumento aparente en función de la Composición y la División, así como con el que se da en virtud de la Acentuación. Dejo para más adelante (sección III) las implicaciones que tendría esto para la interpretación de estas falacias en $S E$.

\footnotetext{
${ }^{7}$ Para los fines del presente artículo no es necesario adentrarse en los detalles de esta práctica argumentativa, cuyos lineamientos pueden encontrarse especialmente en Top., I y VIII.

${ }^{8}$ Para una consideración sobre los diferentes niveles o ámbitos en los que tendrían aplicación las $S E$, puede verse también L. A. Dorion, 1995, pp. 56-58; J. Woods, 1999, p. 204. Para la aplicación propiamente filosófica de las $S E$ me permito remitir a G. Rossi, 2006.
}

${ }^{9}$ I. Düring, 1966, pp. 28-29, subraya el apodo de "lector" que habría recibido Aristóteles en la Academia debido a su actividad dirigida a la lectura de libros a diferencia de la práctica usual de escucharlos. El autor considera que esta característica de no-oralidad expresa además una diferencia fundamental entre Aristóteles y Platón en lo que se refiere al estudio de las opiniones de otros pensadores (menospreciado por el segundo según la concepción tradicional, considerado fundamental por el primero; cf. la nota siguiente). Sobre la extensa biblioteca que habría reunido Aristóteles para la realización de esta tarea, véase por ejemplo W. Jaeger, 1946, p. 385; H. Hunger et al., 1961, tomo I, pp. 62-63 y 217-218.

${ }^{10}$ Vale recordar que uno de los órgana dialécticos, el que consiste en conseguir las

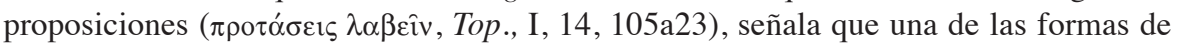


Se ha insistido mucho, y con razón, sobre los puntos de contacto que existen entre la dialéctica y la retórica tal y como las concibe Aristóteles. ${ }^{11}$ Y no hay más que recordar la sentencia inaugural de $R h$. ("la retórica es la contraparte de la dialéctica" ${ }^{12}$ ) para que resulte evidente que se da entre ambas un juego de semejanzas, analogías y puntos de contacto, uno de los cuales, entre las dos disciplinas, es precisamente la correspondencia entre el argumento dialéctico y el retórico o entimema, ${ }^{13}$ y del entimema aparente ( $\varphi \alpha$ เvó $\left.\mu \varepsilon v o v ~ \varepsilon ́ v \theta v ́ \mu \eta \mu \alpha\right)$ y el argumento aparente en sede dialéctica ( $\varphi \alpha v$ ó $\mu \varepsilon v o \varsigma \sigma v \lambda \lambda \circ \gamma \imath \sigma \mu o ́ \varsigma) .{ }^{14}$ Puesto que hay argumentos que son tales y otros que sólo aparentan serlo, habrá en consecuencia también entimemas que son tales (podría pensarse naturalmente en los expuestos en el capítulo $R h$., II, 23), y otros que, no siéndolo, parecen serlo. Estos últimos son estudiados por Aristóteles en $R h$., II, 24.

Dado que el planteamiento de $S E$, como es reconocido casi unánimemente, ${ }^{15}$ es anterior al de $R h$., II, 24, siempre se ha tomado al segundo como una aplicación del primero, o como un mero recordatorio de las falacias ya estudiadas en el primer tratado. ${ }^{16}$ Esta impresión surge, además, por la falta de sistematicidad y el poco cuidado con que Aristóteles expone las falacias en $R h$., en particular si se compara con el detallado tratamiento que encontramos en $S E$.

Por mi parte, quiero defender la tesis según la cual, tras un examen detenido de ambos planteamientos, pueden encontrarse elementos que llevan a pensar que, más que una mera aplicación o recopilación del viejo material, hay en $R h$., en muchos casos una reelaboración, o bien, más radicalmente, una innovación respecto de dicho tratado. En segundo lugar, defenderé el argumento subsidiario según el cual esta reelaboración puede explicarse en función de las características propias

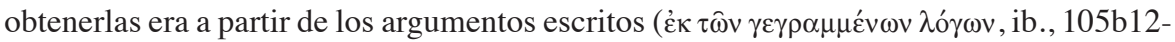
3 ), confeccionando a partir de esto listas ordenadas por tema y autor, encabezadas por epígrafes.

${ }^{11}$ Cf., entre otros, S. Raphael, 1974; J. Sprute, 1982 y J. Brunschwig, 1994.

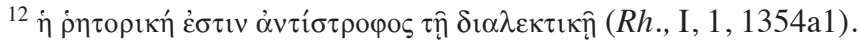

${ }^{13}$ Cf. Rh., I, 1, 1355a10-14, y en el mismo sentido 1356a34 ss.; 1357a15-16.

${ }^{14}$ Rh., 1356a35-b4; 1397a3-4; 1400b34-1401a1.

${ }^{15}$ La única excepción que conozco es Spengel, 1867, ad 1400b38; cf. ib., ad 1401b9.

${ }^{16}$ Véase, por ejemplo, C. L. Hamblin, 1970, pp. 71-72; Q. Racionero, 1990, p. 126. 
de la argumentación retórica y de sus diferencias con la argumentación dialéctica. Es decir, procuraré no sólo mostrar que hay cambios de contenido entre uno y otro tratamiento de lo falaz, sino además, encontrar un fundamento para esos cambios en algunas diferencias que pueden constatarse entre la argumentación en sede tanto dialéctica como retórica. En efecto, tal como se reconoce la fuerte cercanía entre dialéctica y retórica, no menos cierto es que ambas se contraponen en varios aspectos. Si estoy en lo cierto, el tratamiento de $R h$. constituiría un aporte que resulta en muchos sentidos original, pues en este texto Aristóteles no se limita a reproducir el viejo material de $S E$.

Existen diferencias entre ambas listas de falacias que es posible constatar a primera vista, dado que se trata de cuestiones de orden nominal (es decir, falacias con diferentes nombres); pero no me detendré aquí en este tipo de distinciones más o menos evidentes. En cambio, me propongo considerar las diferencias que se esconden bajo ciertas aparentes coincidencias nominales entre ambas listas. Es decir, falacias que aparecen en la clasificación de refutaciones aparentes de $S E$ y en la clasificación de entimemas aparentes de $R h$., II, 24, pero que, ante un examen detenido, se revelan como estructuras argumentativas diferentes. Dicho de otro modo, hay falacias aparentemente presentes en ambas listas pero que no tienen en común entre sí más que el nombre. Se trata de la falacia del Accidente, la Falsa Causa, la Composición y la División. Estos casos me parecen interesantes porque muestran más ejemplarmente, a mi entender, hasta qué punto el planteamiento retórico sobre el entimema aparente habría sido fruto de una reflexión que guarda un alto grado de independencia respecto del estudio dialéctico sobre el argumento aparente.

En este artículo, analizaré con detalle las falacias de Composición y División en su versión retórica y en su versión dialéctica, con el objeto de comprender cada uno de los planteamientos en sí mismos, constatar y explicar las diferencias entre ambos, y ofrecer de este modo un caso ejemplar en el que puede verse cómo, y hasta qué punto, dos falacias homónimas no implican una aplicación de lo estudiado en sede dialéctica, sino que involucran una reformulación en su versión retórica.

Comenzaré con una exposición de la versión dialéctica de este argumento aparente, para pasar después al caso retórico y constatar las diferencias entre ellos. Por último, explicaré estas diferencias entre ambos tratamientos en función de algunas características propias de la argumentación dialéctica y retórica respectivamente. 
Ante todo, es preciso ubicar los argumentos aparentes por la composición y la división dentro de la clasificación general que realiza Aristóteles en $S E 4$ y 5 . Como se sabe, Aristóteles divide los tipos de argumentos aparentes en dos grandes grupos: aquellos que se dan en virtud del lenguaje

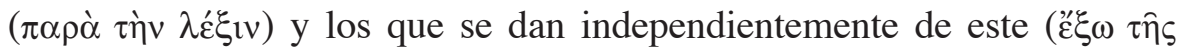

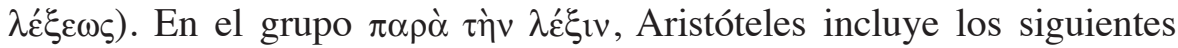
tipos de argumentos aparentes: la Homonimia, ${ }^{17}$ la Anfibolía, ${ }^{18}$ la Composición, ${ }^{19}$ la División, ${ }^{20}$ la Acentuación, ${ }^{21}$ y la Semejanza en la Forma

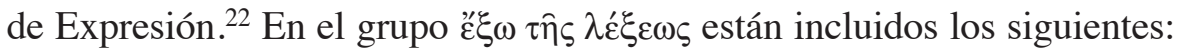
el Accidente, ${ }^{23}$ el decir algo de manera absoluta o bajo algún aspecto (Secundum Quid), ${ }^{24}$ el no distinguir la definición de la refutación (Ignoratio Elenchi), ${ }^{25}$ la Petición de Principio, ${ }^{26}$ el Consecuente o "lo que se sigue", ${ }^{27}$ la Falsa Causa o "tomar como causa lo que no es causa", ${ }^{28}$ y el convertir dos preguntas en una. ${ }^{29}$ No me detendré aquí en los problemas relativos a la distinción misma. ${ }^{30}$ Baste decir, para nuestros propósitos, que los argumentos aparentes en virtud del lenguaje tienen su origen en

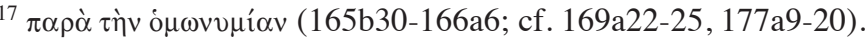

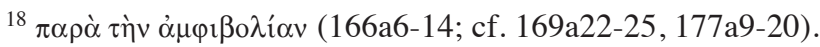

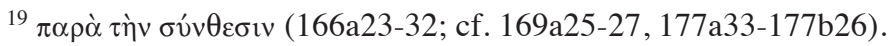

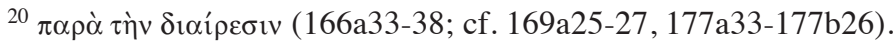

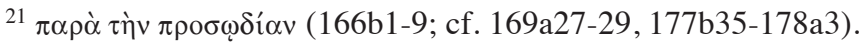

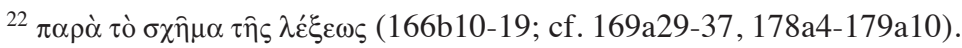

${ }^{23} \pi \alpha \rho \grave{~ \tau o ̀ ~ \sigma v \mu \beta \varepsilon \beta \eta к ́ ́ \varsigma ~(166 b 28-36 ; ~ c f . ~ 168 a 34-168 b 10, ~ 169 b 3-9, ~ 179 a 27-179 b 5) . ~}$

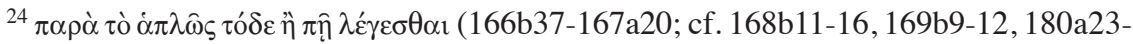
$180 \mathrm{~b} 39$ ).

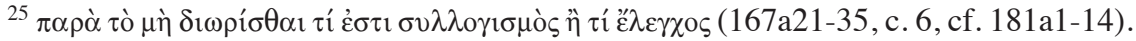

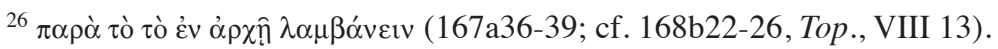

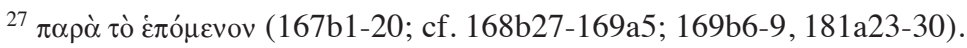

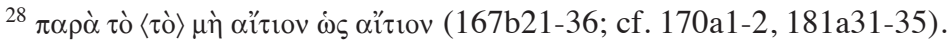

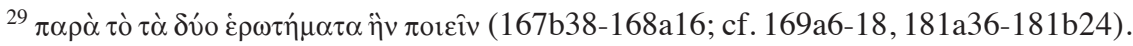

${ }^{30} \mathrm{Se}$ trata de un asunto debatido, sobre todo en lo que se refiere al segundo grupo de argumentos aparentes: los que se dan independientemente del lenguaje. Como puede verse, este grupo es definido por la negativa, con lo cual no queda claro cuál es la característica común que poseen todos los argumentos así agrupados. S. Ebbesen, 1981, tomo I, p. 7, señala precisamente que los principios que subyacen a esta gran división de argumentos en $S E$ nunca son claramente expuestos. Desde las interpretaciones más antiguas 
la expresión lingüística considerada en su materialidad, la cual da lugar a una ambigüedad sobre la que se apoya el argumento aparente. ${ }^{31}$

Las falacias de Composición y División en $S E$, de este modo, caen

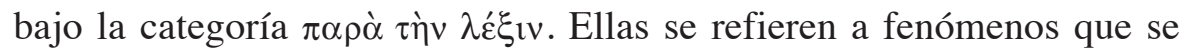
darían en el plano del enunciado ( $\lambda$ ó $\varsigma_{\text {o }}$ ), más puntualmente, a la agrupación de las palabras en éste, dado que, en ciertos casos, un conjunto de vocablos dichos de corrido (i. e. sin pausa alguna) o divididos en uno $\mathrm{u}$ otro punto ${ }^{32}$ no mantiene el mismo significado.

Veamos algunos ejemplos de estas falacias en $S E, 4$ :

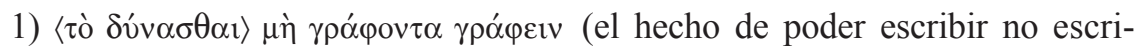
biendo) (166a27-28).

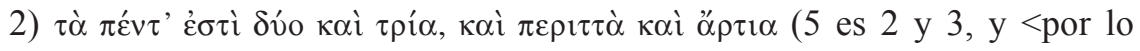
tanto $>$ par e impar) (166a33-34).

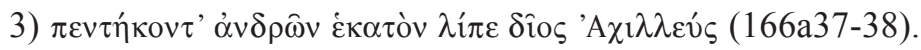

1) Este caso es presentado como un ejemplo de Composición. El enunciado en cuestión, si se lo considera de modo compuesto (i. e. sin

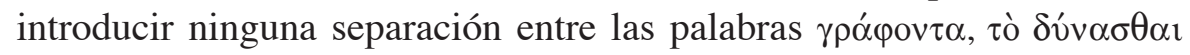
y $\gamma$ $\rho \alpha ́(\varphi \varepsilon \imath)$, significa que alguien tiene la capacidad de escribir no escribiendo (algo manifiestamente absurdo); pero si no se compone (i. e.

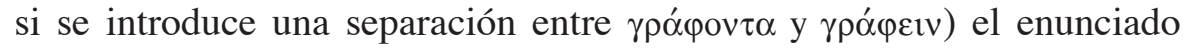
significa que alguien, cuando no escribe, tiene la capacidad de escribir. Esta explicación es provista por el propio Aristóteles (166a27-30) quien recurre, para marcar la diferencia de significado entre una y otra forma de decir la sentencia, a distintas construcciones sintácticas: en el caso de la frase compuesta el "no escribir" es expresado por un participio con

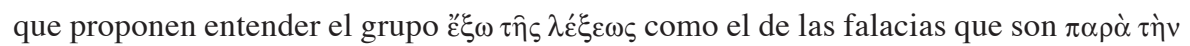

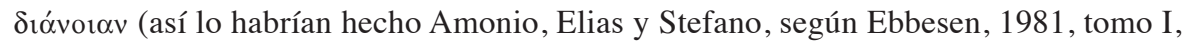
p. 127; cf. también Ps. Alejandro, in SE, 5.18-20), hasta las interpretaciones modernas que entienden los argumentos aparentes del grupo $\varepsilon^{\prime} \xi \omega \tau \eta_{\varsigma} \lambda \varepsilon^{\prime} \xi_{\varepsilon \omega \varsigma}$ como violaciones de leyes lógicas o errores de razonamiento (cf., por ejemplo, Dorion, 1995, p. 70-72). Estos intentos, sin embargo, no resultan del todo satisfactorios. Muy brevemente, hay varios casos de argumentos aparentes clasificados como $\varepsilon^{\prime} \xi \omega \tau \uparrow \varsigma \lambda \varepsilon_{\varepsilon} \xi \omega \varsigma$ que, estrictamente, no consisten en errores de razonamiento o de inferencia, como el posteriormente llamado secundum quid y la petitio principii.

${ }^{31} \mathrm{El}$ grupo de los argumentos aparentes que se dan independientemente del lenguaje no parece ser tan homogéneo.

${ }^{32}$ Cf. $S E, 166$ a24-30 y 35-36. 
valor adverbial (de igual modo que en la frase en cuestión), mientras que para señalar la forma no compuesta, se expresa el "no escribir" mediante una oración subordinada adverbial temporal, la cual indicaría más explícitamente el sentido que habría de darse al participio en la fórmula original, sentido que quedaría claro al pronunciar las palabras de modo separado y no de corrido.

En definitiva, es claro que el error aquí surge a causa de "componer" los distintos elementos de la frase o, dicho de otro modo, por leer la frase de corrido, en lugar de introducir una separación entre el participio

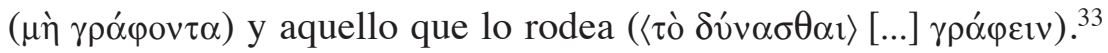

2) Este caso es presentado como un ejemplo de División, en el cual la conclusión absurda (cinco es par e impar) deriva de entender la premisa dividida en cierta forma antes que en otra; siguiendo la lectura de R. Edlow (1977, p. 26), el error surge por entender "5 es 2 y 3" (parafraseando: "5 es 2" y "5 es 3"), como si 2 y 3 fuesen dos cosas que se predican por separado de 5, es decir, como si el кoí estuviera coordinando dos oraciones independientes. En cambio, 2 y 3 deben entenderse como

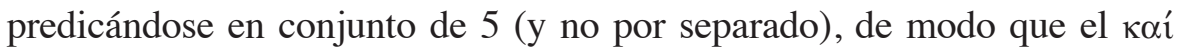
no coordina dos oraciones, sino dos predicativos de un solo sujeto en una sola oración. Es decir, se trata, desde el punto de vista gramatical, de dos predicativos, pero, desde el punto de vista lógico, de un predicado, compuesto por ambos, puesto que se trata de una sola propuesta. El equívoco surge al tomar este predicado compuesto por estos dos predicativos $\mathrm{y}$, dividiéndolos, tomarlos como dos predicados (por lo tanto, se trataría de dos oraciones-proposiciones). La ambigüedad que surge de la frase puede eliminarse, como en el caso anterior, introduciendo o eliminando pausas entre las palabras (cf., por ejemplo, L. A. Dorion, 1995, ad 166a38). ${ }^{34}$

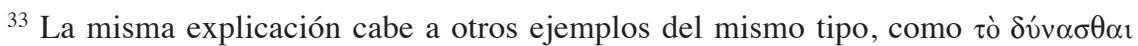

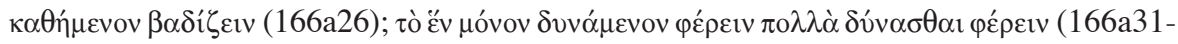
32). Puede verse para estos ejemplos además el interesante análisis de A. Schiaparelli, 1999, pp. 58-59, quien identifica en estos ejemplos un error específico en términos del radio de acción del operador modal ( $\delta \dot{v} v \alpha \sigma \theta \alpha \mathrm{l})$.

${ }^{34}$ Ya Hamblin, 1970, p. 84, a pesar de que su análisis de este error difiere del expuesto aquí, sugiere que no sería irrazonable para Aristóteles sugerir que la distinción entre los sentidos de esta frase fuera hecha al pronunciarla de diferentes modos. No coincido con la lectura de A. Schiaparelli, 1999, p. 59-60, quien concluye que se trata aquí de un error análogo al señalado en los modernos libros de lógica, que consiste en atribuir al todo las propiedades de las partes. 
Otro ejemplo que corresponde a este mismo tipo de argumento apa-

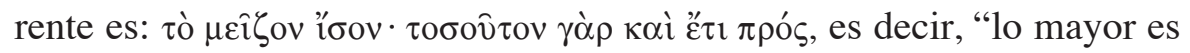
igual, dado que es igual de grande y algo más" (166a34-35); en efecto, habría que pensar que aquí se parte de afirmar que "lo mayor es igual de grande y algo más", y de entender que los predicados ("ser igual de grande" y "ser algo más") se dicen por separado del sujeto, y no en conjunto (del mismo modo que sucedía con el 2 y el 3 respecto del 5). De ahí que pueda concluirse que lo mayor es igual.

3) En el tercer caso, ofrecido como ejemplo de División, la separación entre las palabras cambia radicalmente el sentido de la frase dependiendo de dónde sea introducida; por ello al enunciarlo más arriba he omitido incluso una traducción del mismo: si se introduce una pausa después de $\dot{\alpha} v \delta \rho \hat{\omega} v$, con lo cual éste recibiría como atributo el adjetivo numeral $\pi \varepsilon v \tau \eta ́ \kappa \kappa o v \tau \alpha$ (cincuenta), la frase significa "el divino Aquiles dejó cien de cincuenta hombres" (algo, por cierto, imposible). En cambio, si se introducen pausas después de $\pi \varepsilon v \tau \eta ́$ коv $\tau \alpha$ y después de

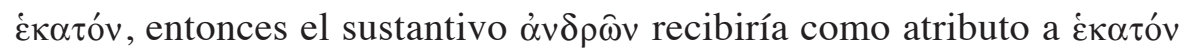
(cien), con lo cual la frase significa "el divino Aquiles dejó cincuen-

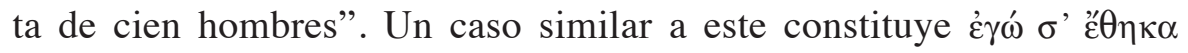

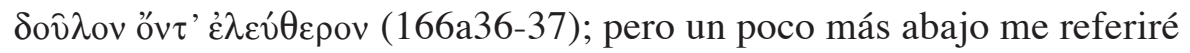
a sus posibles dos significados según el punto en donde se operen las divisiones.

\section{III}

Como se puede ver, la Composición y la División, tal como son definidas en $S E$, dependen de un modo u otro de la separación o ligazón sintáctica entre diferentes palabras de una frase,${ }^{35} \mathrm{y}$ a ello se hace referencia justamente con la denominación de estos argumentos aparentes (i. e. “composición” y "división”). En esta sección procuraré precisar cuáles son las condiciones en que pueden darse estas falacias así definidas.

En un par de pasajes (SE, 168a23-28; cf. 177b7-9) Aristóteles divide las falacias del grupo $\pi \alpha \rho \grave{\alpha} \tau \grave{\eta} \nu ~ \lambda \varepsilon^{\prime} \xi_{\text {iv }}$ en dos subgrupos según el error se

${ }^{35}$ Es cierto, sin embargo, que en el análisis de los distintos ejemplos pueden emplearse fructíferamente diversas nociones teóricas, tal como muestra A. Schiaparelli, 1999, p. 56-60; sin embargo, es preciso subrayar - y aquí me alejo de la lectura de Schiaparelli - que todos los ejemplos dependen de un error común que concierne a la división o composición sintáctica de las palabras en la oración. 
produzca a causa de una ambigüedad en el lenguaje o no. ${ }^{36} \mathrm{R}$. Edlow señala que la subdivisión de Aristóteles respondería a la distinción entre "ambigüedad lingüística" y "confusión lingüística" (apoyándose en los pasajes de $S E$ recién mencionados) ${ }^{37}$ De este modo, la Homonimia, la Anfibolía y la Semejanza en la Forma de Expresión tendrían lugar a partir de una ambigüedad en el lenguaje, es decir, por el hecho de que una misma palabra (óvo $\mu \alpha$ ) o un mismo enunciado ( $\lambda$ ó $\gamma$ s) significa dos cosas diferentes; una característica que es explotada por ciertos

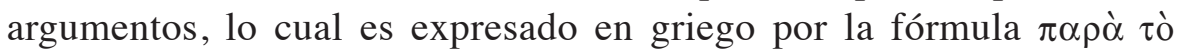

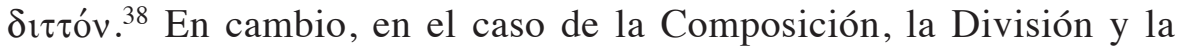
Acentuación, no se trataría propiamente de una ambigüedad, puesto que no es un mismo enunciado o palabra el que significa dos cosas diferentes, sino que son más bien dos enunciados (en el caso de la Composición y la División) o dos palabras (en el caso de la Acentuación) distintas que se confunden entre sí; de ahí que Edlow califique este error como una "confusión lingüística". En efecto, en estos casos, el enunciado o la palabra parecen ser idénticos, pero en realidad son distintos, y por lo tanto hay en juego, naturalmente, dos significados distintos. Esto resulta suficientemente claro a partir del pasaje de $S E$ antes mencionado:

Pues de los [argumentos aparentes] que $<$ se dan $>$ en el lenguaje, unos son en virtud del doble sentido, como la Homonimia y el Enunciado [i. e. Anfibolía] y la Semejanza en la Forma de Expresión (pues es costumbre $<$ tomar $>$ todas las cosas como si significaran un esto ( $\tau$ ó $\delta \varepsilon \tau \imath$ ), por otro lado, la Composición, la División y la Acentuación $<$ se dan $>$ por el hecho de no ser el mismo el enunciado o $<$ ser $>$ diferente la palabra (168a23-28).

${ }^{36}$ Cf. L. A. Dorion, 1995, p. 78 y ss.

${ }^{37}$ R. Edlow, 1977, p. 21. Según este mismo autor, la lectura de Galeno en De Captionibus, justamente, no es ortodoxa porque considera que todos los argumentos apa-

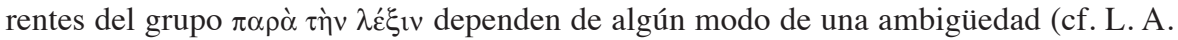
Dorion, 1995, p. 82).

${ }^{38}$ Este concepto, presente en Galeno, habría sido la principal contribución de Alejandro de Afrodisias en su comentario perdido a las $S E$ según C. L. Hamblin (1970, p. 98), quien incluso atribuye a Alejandro la distinción de $\tau$ ò $\delta \imath \tau$ óv en tres clases (también presente en Galeno): actual, potencial e imaginario (Ib., pp. 99-100). También se ha señalado como fuente de esta lectura de Galeno un tratado perdido de Eudemo, y en tal sentido se propone que ciertas partes del tratado del primero serían fragmentos de aquél tratado perdido; sin embargo, esta posibilidad es desestimada por Fortenbaugh, 2002. 
Como puede verse, los tres últimos argumentos aparentes no serían ambiguos porque no satisfacen el criterio de identidad del nombre / enunciado. En efecto, en 177b1-3 ésta es justamente la diferencia que Aristóteles marca entre la División y la Ambigüedad: ${ }^{39}$ no es ambiguo ( $\delta \imath \tau$ cóv) lo que se da en virtud de la División, pues en la División el enunciado no deviene ( $\gamma^{\prime}$ ve $\tau \alpha$ ) ) el mismo una vez dividido.

Tomemos el ejemplo que ofrece Aristóteles en 166a36-37:

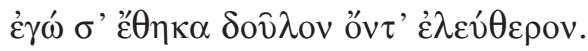

Según las afirmaciones anteriores de Aristóteles, entonces, hemos de encontrar los dos enunciados diferentes que resultan de decir estas palabras de corrido e introduciendo pausas, que podemos marcar por

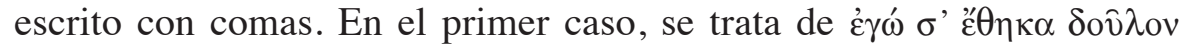
őv $\tau$ ' $\dot{\lambda} \lambda \varepsilon \dot{v} \theta \varepsilon \rho o v$ ("yo te hice esclavo cuando eras libre"). En el segundo

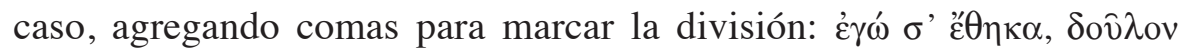

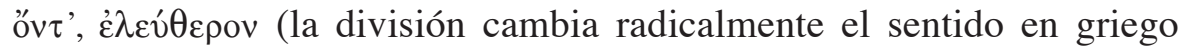
al cambiar el predicativo del participio: "yo te hice libre, cuando eras esclavo"). Así, un conjunto de palabras separadas entre sí mediante una pausa en determinado lugar será un enunciado materialmente diferente del mismo conjunto de palabras enunciadas sin pausa alguna (o introduciendo una pausa en otro lugar), razón por la cual no cabe hablar estrictamente de ambigüedad. ${ }^{40}$

Con todo, existe el siguiente problema: Aristóteles afirma en otros pasajes que el mismo enunciado (ò $\alpha$ vò̀ $\lambda$ ó $\gamma_{0 \varsigma}$ ) compuesto y dividido no significa lo mismo (166a35-36, cf. 177a34-35), e incluso, que los seis argumentos aparentes $\pi \alpha \rho \grave{\alpha} \tau \grave{\eta} v ~ \lambda \dot{\varepsilon}^{\xi} \xi_{\mathrm{iv}}$ agotan todos los modos en que no se indica lo mismo con los mismos nombres y enunciados ( $\tau$ oîs

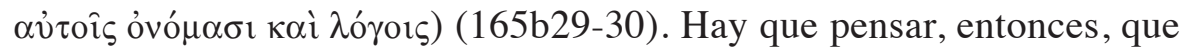
el enunciado y la palabra, en el caso de la Composición, la División y la Acentuación, son en algún sentido el mismo (y esto explicaría por

${ }^{39}$ J. Evans, 1975, p. 47, en cambio, entiende que en este pasaje de $S E$ hay una asimilación entre Anfibolía y División. Para una discusión de la interpretación de Evans, véase L. A. Dorion, 1995, ad 177b1, con cuya lectura del pasaje coincido.

${ }^{40}$ Algo análogo ocurre en el caso de la Acentuación, pues es evidente que ópos y öpos (177b3-4), a pesar de que contienen las mismas letras, no son la misma palabra dado que cambian los espíritus y acentos (la $\pi \rho \circ \sigma \omega \delta$ día incluiría tanto a unos como a otros). 
qué puede confundirse uno por otro) y en otro es diferente. Esto nos permite advertir un aspecto relevante de estos argumentos aparentes: ${ }^{41}$ el enunciado y la palabra son idénticos cuando están escritos, es decir, hay un elemento de ambigüedad, o más bien de indeterminación, en el lenguaje escrito, el cual desaparece una vez que la palabra o el enunciado es pronunciado oralmente y de ese modo deviene unívoco. Este doble significado o indeterminación que tendría la palabra o la frase escrita, se entiende si se tienen en cuenta las condiciones de la escritura en el siglo IV a. C., concretamente la ausencia de signos de puntuación escritos (como las comas que dividirían un enunciado), ${ }^{42}$ de $\operatorname{acentos}^{43}$ y de espíritus. Más aún: tampoco las palabras aparecían separadas entre sí por medio de espacios, sino que se practicaba la escritura continua (a pesar de que ninguno de los ejemplos que ofrece Aristóteles de las falacias de composición y división derive de una confusión a raíz de la división entre palabras ${ }^{44}$ ). Retomando los ejemplos ofrecidos por Aristóteles, habría que pensar que en el caso de la Acentuación, un lector del s. IV a.C. encontraría la palabra OPO $\Sigma$ (así escrita), y, mientras la misma no fuera pronunciada, evidentemente mantendría ambas posibilidades de significación (őpos u őpos) y por lo tanto es ambigua, o mejor dicho, no se sabe qué palabra es. En cambio, si ese vocablo es expresado oralmente desaparece toda ambivalencia, pues necesariamente es pronunciado de un modo o de otro (cf. 178a2-3). Confirmando en

${ }^{41}$ En este punto sigo la respuesta que ofrece L. A. Dorion a este problema (cf. Dorion, 1995 , p. 84 y su nota ad 166a38, y ad 168a28, p. 245-248).

${ }^{42}$ R. Edlow, 1977, p. 27-28, L. A. Dorion, 1995, p. 84 y 246. Cf. H. Hunger et al., 1961, tomo I, p. 74; F. Kenyon, 1951, p. 67; E. Turner, 1968, p. 57 y 99.

${ }^{43}$ Como se sabe, el origen de los acentos escritos habría ocurrido alrededor del año 200 a.C., cuando fueron introducidos por Aristófanes de Bizancio como medio de enseñar a los extranjeros la correcta pronunciación del griego (W. Goodwin, 1894, p. 26). Los acentos comienzan a encontrarse recién en papiros literarios del s. I a. C., pero se limitaban a los textos más difíciles, y aún allí eran puestos sólo esporádicamente $(\mathrm{H}$. Hunger et al., 1961, tomo I, p. 80).

44 De todos modos, esto podía constituir una fuente de equívocos al momento de interpretar un texto en escritura continua. S. Ebbesen, 1981, tomo I, p. 188, aporta en este sentido el ilustrativo caso de Plinio que, en su historia de los animales, cuenta entre los animales marinos un extraño ratón ( $\dot{\eta} \delta \grave{\varepsilon} \mu \hat{v} \varsigma$ ), que sale del mar a la costa a poner sus huevos en un agujero, y pasado un mes retorna para llevar su cría al mar. Todo indica que este extraño ratón es la tortuga marina que menciona Aristóteles en $H A$, 558a6-11:

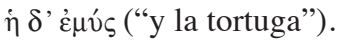


alguna medida esta interpretación, Aristóteles señala en $S E, 4$ (166b13), cuando presenta el argumento aparente en virtud de la Acentuación, que éste no sería fácil de construir en las discusiones dialécticas no escritas (puesto que oralmente la palabra no sería indeterminada y por lo tanto tendría un solo sentido), sino que se da más bien en los escritos y poemas.

El caso de la Composición y la División podría pensarse en términos similares a la Acentuación, dado que, como vimos, tampoco había signos de puntuación en la escritura del s. IV a. C., y, por lo tanto, las pausas entre los distintos elementos del enunciado sólo podían hacerse evidentes mediante la pronunciación del mismo y no por escrito. Esto parece plausible, además, por la cercanía que Aristóteles plantea entre Acentuación, Composición y División, como se vio en 168a23-28, en donde las tres integran uno de los subgrupos dentro de las falacias $\pi \alpha \rho \grave{\alpha}$

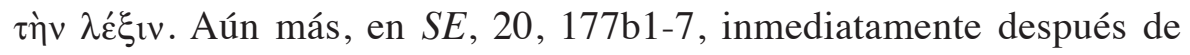
afirmar que la División no es ambigua porque no se trata del mismo enunciado una vez que ha sido dividido, Aristóteles considera el caso de la Acentuación, y afirma que en los argumentos escritos el nombre es el mismo siempre que esté escrito con las mismas letras y de la misma manera, "pero las cosas dichas no son las mismas. De modo que la falacia en virtud de la División no es ambigua." (177b6-7, las cursivas son mías). La conclusión de este pasaje resulta un tanto sorprendente, a menos que se entienda que Aristóteles está equiparando lo que sucede en el caso de la Acentuación, en donde una palabra es la misma en tanto está escrita, pero no lo es cuando es pronunciada (y por lo tanto no es ambigua), con lo que sucede en la División, que no es ambigua porque el enunciado, una vez dividido (= pronunciado), no es el mismo. C. L. Hamblin parece apuntar en este mismo sentido -aunque no por las mismas razones- cuando, al considerar los ejemplos de División que ofrece Aristóteles en $S E, 20$, señala: "what distinguishes these cases from amphiboly, then, is that although the double-meaning occurs in the written form, it is removed -or, at least, can be removed-when the words are spoken aloud" (p. 83).

Podemos concluir, entonces, que los argumentos aparentes de Composición y División, tal como son tipificados por Aristóteles en $S E$, se fundan en un elemento de indeterminación propio del lenguaje escrito y que esta indeterminación se apoya, a su vez, en las características propias de la escritura en el s. IV a. C. Este elemento de indeterminación 
desaparece en el lenguaje oral ${ }^{45}$ es decir, una vez que el enunciado en cuestión es verbalizado.

Si estoy en lo cierto, se sigue de aquí que este tipo de argumentos aparentes, tal y como aparecen en $S E$, no encuentran hoy día instancias de aplicación, pues actualmente no tenemos ninguna dificultad para indicar por escrito - tanto como oralmente - las pausas que han de hacerse en las frases de acuerdo con el sentido de las mismas. Quizá por eso la composición y la división no han sobrevivido hasta hoy tal como Aristóteles las define en su versión dialéctica. Como veremos en seguida, es su versión retórica la que ha llegado a nosotros bajo el nombre de Composición y División.

IV

En esta sección presentaré y analizaré el tratamiento de la Composición y la División en $R h$., II, 24. Dado que el tipo de argumento propio del ámbito retórico es el entimema, en este caso la Composición y la División son presentadas como tipos de entimemas aparentes. Según explica Aristóteles, el entimema aparente de la Composición y la División es aquél que consiste en decir lo dividido de forma compuesta o lo compuesto dividiéndolo, puesto que parece ser lo mismo (es decir, parece ser indistinto lo compuesto y lo dividido), pero muchas veces no lo es. ${ }^{46}$

En primer lugar, y antes de presentar y analizar los ejemplos de Composición y División que ofrece Aristóteles en la $R h$., es importante constatar una diferencia inicial con el modo en que son presentadas y clasificadas las falacias homónimas en $S E$. Me refiero a lo siguiente: mientras que en $S E$ la Composición y la División eran dos tipos de ar-

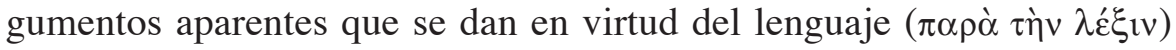
por involucrar una cierta ambigüedad, en $R h$., II 24 , en cambio, ya no se

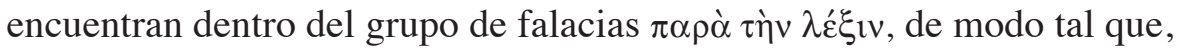

${ }^{45}$ Con esto mi lectura se aleja de la que ofrece A. Schiaparelli, 1999, respecto de la División en $S E$. Esta autora entiende que la falacia se produce por una intención del hablante de significar algo profiriendo una expresión unida y una mala interpretación del oyente que la comprende como separada. Sin embargo, la autora no parece haber tenido en cuenta las características de la escritura en el s. IV a. C., si se atiende a la siguiente afirmación respecto de la Composición marcando su diferencia con la Anfibolía: “[...] pronunciare o scrivere [...] con le dovute pause o $i$ segni di interpunzione comporta in qualche modo un chiarimento semantico" (p. 58, las cursivas son mías).

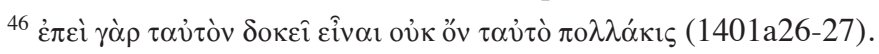


puede pensarse, ellas exceden el plano lingüístico. ${ }^{47}$ Esto es confirmado por los ejemplos de estos entimemas aparentes que ofrece Aristóteles en $R h .:$ como en seguida veremos, ninguno de estos ejemplos muestra un posible doble sentido fundado en diferentes modos de dividir o componer el enunciado mismo; por el contrario, ellos se refieren a relaciones parte-todo.

En segundo lugar, dado que Aristóteles afirma que decir lo dividido de forma compuesta (o lo compuesto de forma dividida) muchas veces no es lo mismo, podemos pensar que no necesariamente todos los casos en que se compone o se divide constituyen, por ello, entimemas aparentes, es decir, que el carácter falaz o válido del entimema no deriva de su sola forma, sino que ello debe ser determinado en cada caso atendiendo al aspecto material de las premisas y la conclusión. ${ }^{48}$ En particular, como se verá a partir de los ejemplos que ofrece Aristóteles, estas consideraciones habrán de referirse a la naturaleza de las relaciones parte-todo, de modo tal que la fuente del paralogismo reside en componer en un todo nociones válidas por separado o en aplicar a las partes nociones válidas respecto del todo, en ciertos casos en que esto no es lícito. De aquí se sigue, claro está, que estas falacias estudiadas por Aristóteles en Rh., II, 24 no pueden ser definidas en términos puramente formales. Esto es un rasgo compartido por las aproximaciones modernas a estos tipos de errores argumentativos, ya que Composición y División son consideradas en los actuales tratados de lógica como falacias "no-formales".

En Política, II, 5, 1264b15-22 encontramos una discusión respecto de las relaciones parte-todo que ilustra esta necesidad de determinar en cada

${ }^{47}$ En el tratamiento de $R h$., II, 24, los entimemas aparentes que se encuentran den-

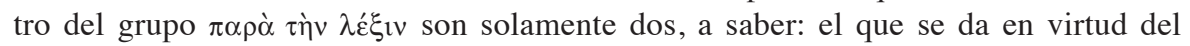

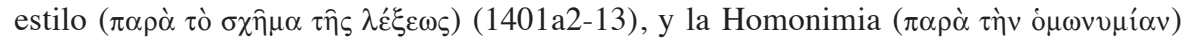
(1401a13-25). Nada queda en $R h$. de la Acentuación, la Anfibolía y la Forma de la Expresión y, estrictamente, tampoco de la Composición y la División. Vale aclarar, además,

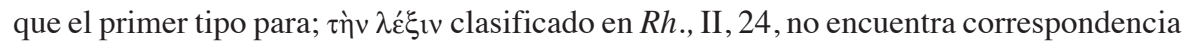
en $S E 4$, sino en $S E 15,174 b 8-11$. Este caso no sería a causa de una ambigüedad en el

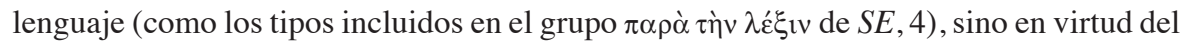
estilo $\left(\lambda \varepsilon^{\prime} \xi_{1 \varsigma}\right.$ ha de tomarse aquí en este sentido, cf. Cope-Sandys, 1877, vol. II, p. 304, ad loc.), en concreto, el estilo periódico antitético, que da con mayor facilidad la apariencia de un argumento, cf. Rh., III, 9, 1409b33-1410a23.

${ }^{48}$ Puede verse $R h .$, II, 19, 1392a27-31 para un caso en que el todo y las partes sí pueden recibir una misma noción o propiedad (en este caso el ser posibles); cf. II, 23, 1397a28-1397b11, en donde se considera un caso en que esto resulta falaz. 
caso las características del objeto sobre el que versa el argumento y la imposibilidad de reducir la cuestión a un error formal. Allí, en el marco de las críticas al modelo político propuesto por Platón en República, Aristóteles cuestiona que la ciudad entera pueda ser feliz, siendo que se estipula que los guardianes no han de serlo. ${ }^{49} \mathrm{Y}$ señala al respecto que el ser feliz como predicado de un todo no es igual al ser par: el ser par puede suceder al todo sin suceder a ninguna de sus partes; en cambio, es imposible que esto suceda con la felicidad. En este pasaje de la Pol. se detectan dos predicados que tienen características diferentes: uno de ellos - "ser feliz" - sólo es verdadero del todo si lo es también de las partes (todas o la mayoría), y el otro - "ser par" - puede ser verdadero del todo con independencia de ser verdadero o falso de las partes. Este tipo de reflexiones y distinciones respecto de la naturaleza del "todo" acerca del cual se delibera o argumenta serían indispensables para no cometer la falacia de Composición ni la de División, como se verá más claramente a continuación, al considerar los ejemplos de este entimema aparente que ofrece Aristóteles. ${ }^{50}$ Estos ejemplos muestran $a$ ) por un lado, discursos en donde se aplican ilícitamente a las partes nociones que se dicen del todo (División), y $b$ ) por otro, enunciados en los que se componen en un todo nociones que sólo son aplicables por separado (Composición).

Los ejemplos que ilustran el caso $a$ ) son los siguientes:

I) Afirmar que se saben las letras porque se conoce la palabra, pues la palabra es lo mismo <que las letras>. (1401a29-31). ${ }^{51}$

II) Puesto que la $<$ dosis $>$ doble es dañina para la salud, decir que la simple tampoco es saludable; pues sería absurdo que, si dos son buenos, uno sea

${ }^{49} \mathrm{El}$ pasaje al que se refiere Aristóteles sería probablemente $R$., IV, 419a-421c, cf. Ib. V, 465e ss. Naturalmente, no discutiré aquí el problema de si la interpretación que Aristóteles realiza de la postura platónica es ajustada o no.

${ }^{50}$ El modo en que Aristóteles trata este tipo de argumentos coincide con análisis modernos de esta misma falacia. Por ejemplo, J. E. Broyles, 1975, p. 108, señala: “[...] some arguments having the parts to whole form are valid deductive arguments and not to be dismissed as fallacious" y concluye un poco más adelante que el solo hecho de que un argumento tenga la forma parte-todo no es condición suficiente para pensar que comete la falacia de composición, de ahí la imposibilidad de abordar esta falacia desde el punto de vista puramente formal. I. Copi, 1972, así mismo, clasifica la Composición y la División como falacias no formales.

${ }^{51}$ Uno de los ejemplos de composición en $S E$, 4, parece coincidir con el ejemplo de $R h$. arriba citado. El texto griego, sin embargo, es poco claro. En la edición de W. Ross 
malo (refutativo); o bien, pues no es posible que si uno es bueno, dos sea malo (demostrativo) (1401a31-34).

El argumento del ejemplo I) parece tomar como punto de partida el hecho de conocer un todo (la palabra), e infiere que se conocen por ello las partes del todo (las letras). ${ }^{52}$ El fundamento de esta derivación es ofrecido después del "pues" ( $\gamma \alpha ́ \rho)$, y consiste en considerar que la palabra es lo mismo ( ò $_{\alpha}$ v่ $\tau^{\text {) }}$ que las letras. Esta proposición que sirve como justificación de la inferencia constituye una instancia de la explicación general de la causa de este paralogismo que ofreció Aristóteles al comienzo (1401a26-27, ver nota 46. En efecto, a partir de este ejemplo resulta claro que el error del argumento no consiste simplemente en afirmar algo respecto de un todo y luego inferir que ello también se dice de las partes, sino que la causa del error es, en verdad, considerar que el todo y las partes son idénticos en los casos en que no lo son. Es decir que la falacia consistiría propiamente en la suposición de una

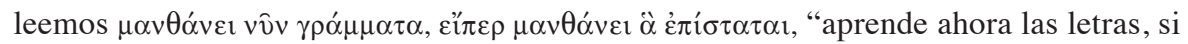
es verdad que aprende lo que sabe" (166a30-31), lo cual no deja demasiado claro el error que involucra el argumento, y ni siquiera el sentido del argumento mismo. L. A.

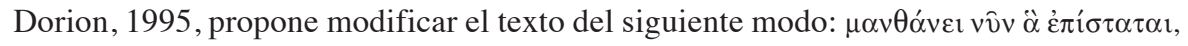

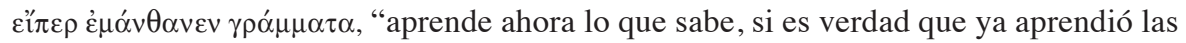
letras". Si la reconstrucción de Dorion es correcta, entonces no se trata de un ejemplo que ponga en juego un problema de ligazón sintáctica, a pesar de que Aristóteles lo presente como un caso de $\sigma u ́ v \theta \varepsilon \sigma i \varsigma$. Este ejemplo en $S E$ es meramente enunciado pero no analizado, lo cual no parece casual, ya que el mismo no resulta explicable a partir de la definición de la falacia que ofrece Aristóteles en $S E$, es decir, no cae bajo el tipo de la Composición tal como ésta es caracterizada en el escrito. En efecto, el argumento constituiría más bien un error en la atribución de propiedades de la parte al todo. Que este tipo de error también puede darse en el ámbito dialéctico resulta además confirmado al encontrar el mismo argumento aparente (y casi el mismo ejemplo) en uno de los argumentos erísticos de que resulta víctima Clinias en el Eutidemo, de Platón (cf. 276d7-277b2). Se trata del argumento acerca de si los que aprenden, lo hacen a partir de lo que conocen o lo que no. Clinias afirma lo segundo y es refutado en virtud del paso ilegítimo de "conocer las letras del alfabeto" a "conocer lo que alguien dicta" (i. e. conocer lo que se dice, pues siempre se dictan letras). Esto implicaría, claramente, que el argumento falaz referido a las relaciones parte-todo puede darse también en sede dialéctica, cf. infra, nota 79 .

52 J. Sprute, 1982, p. 113, nota 224, menciona este ejemplo, pero, al parafrasearlo lo formula en sentido inverso: "aquél que conoce las letras, también conoce una determinada palabra, dado que la palabra es lo mismo que sus letras". Por cierto -si bien en el texto no aparece así- el argumento parece tener más sentido de este modo. 
falsa equivalencia entre el todo y las partes, o, dicho de otro modo, en un error en la caracterización de las relaciones que se dan entre parte y todo en el caso puntual. ${ }^{53} \mathrm{El}$ hecho de que Aristóteles plantee la fuente del error en estos términos permite, además, considerar claramente ambas falacias como modos de un mismo error, lo cual explica por qué no se presentan por separado. Esta identificación errónea llevaría, en definitiva, a considerar que lo que se dice de una ("ser conocido", o "ser justo", o "ser feliz", o "ser saludable", etcétera), puede decirse sin más de las otras o viceversa.

El ejemplo II) obedece al mismo mecanismo, es decir, se parte del hecho de que el todo (una cierta dosis de alguna sustancia) es dañino para la salud y se infiere que una parte de ese todo (la mitad de la dosis) es también dañina. ${ }^{54}$ Aristóteles ofrece dos variantes de este argumento; pero ambas se fundan en el supuesto de la identidad del todo y las partes: en la primera de ellas se aplicarían las propiedades del todo a las partes (sería absurdo que, si dos son buenos, uno sea malo) y en la segunda se aplican las cualidades de las partes al todo (no es posible que si uno es bueno, dos sean malos), por lo tanto, habría que hacer la salvedad de que bajo esta segunda variante el entimema aparente correspondería al modo de la Composición. ${ }^{55}$

Vale la pena mencionar que este tipo de entimema aparente guarda, a su vez, alguna relación estructural con ciertos argumentos megáricos célebres. En efecto, R. Muller menciona el ejemplo de la dosis simple y doble, pero lo identifica como un caso de la falacia de origen megárico conocida como Sorites o el Calvo. ${ }^{56}$ Como se sabe, se trata de dos

\footnotetext{
${ }^{53}$ Esto no quita que, como se ha visto más arriba, haya casos en los cuales lo que se dice del todo se dice también de las partes que lo componen.

${ }^{54}$ En II, 19, 1392b3-5 puede verse un caso en el cual estos términos recíprocos (i. e. simple-doble) sí reciben legítimamente el mismo predicado (v. gr., ser probable).

55 Vale aclarar que en este caso "todo" y "parte" no pueden decirse sin más, pues se trata en realidad de términos relativos (cf. Metaph., V, 15): el doble es un todo en relación con el simple, pero no en sí mismo. El simple es parte en relación con el todo, pero no en sí mismo (pues podría ser todo, por ejemplo, de otras partes que serían simples respecto de él). En este caso, entonces, se trata de un todo cualitativamente diferente que en el caso de la palabra o la ciudad, por ejemplo, dado que este es un todo relativo, i. e., relativamente a algo y no en sí mismo. Sin embargo, hecha esta salvedad, no veo mayores complejidades para entender el error involucrado en el ejemplo.
}

${ }^{56}$ R. Muller, 1985, p. 82. 
formas de un mismo tipo de argumento, que consiste en afirmar que realizando pequeñas y sucesivas adiciones (Sorites) o sustracciones (el Calvo), no ocurre un cambio cualitativo en el todo, o en realidad no puede determinarse en cuál de esas adiciones o sustracciones ocurre dicho cambio. ${ }^{57} \mathrm{~A}$ mi entender, la identificación de un ejemplo de Composición y División con un caso de Sorites o Calvo, si bien no es del todo exacta, permite advertir que hay de hecho una estructura que resulta común entre ambos tipos de argumentos, al menos en ciertas versiones del Sorites y el Calvo. Brevemente: si el Sorites se refiere a una cualidad del todo como la grandeza, la cual - siguiendo la estructura del argumento - no sería alcanzable por adiciones pequeñas, se trataría de un caso en el cual puede afirmarse que las partes son pequeñas y por lo tanto se cree que el todo no puede ser grande. Así, podría considerarse que, en cierto sentido, este argumento cae bajo el tipo descrito en $R h .{ }^{58}$ pues en ambos casos el problema consiste en aplicar los atributos del todo a las partes o viceversa.

Un ejemplo concreto de un caso de intersección entre Composición y Sorites como el que he descrito se encuentra en Pol., V, 8. Allí, en el marco de las consideraciones sobre la conservación de los regímenes, Aristóteles afirma:

En los regímenes bien combinados nada debe vigilarse tanto como que los ciudadanos no quebranten en nada la ley, poniendo especial cuidado en las pequeñeces, porque la transgresión se insinúa sin ser advertida, lo mismo que un pequeño dispendio, repetido con frecuencia, acaba en una fortuna. El gasto pasa inadvertido porque no se hace de una vez. La mente ( $\delta$ ióvor $\alpha$ ) se deja engañar ( $\left.\pi \alpha \rho \alpha \lambda \circ \gamma_{i} \zeta \varepsilon \tau \alpha \iota\right)$ por esos desembolsos, como ocurre con el

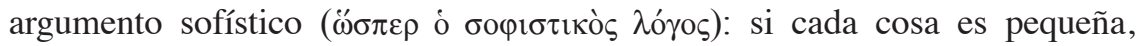
también la totalidad. Pero esto es cierto en un sentido y en otro no: el todo y

${ }^{57}$ Cf. R. Muller, 1988, pp. 140 ss. Por ejemplo, si se arrancan los cabellos de un hombre uno a uno, no podría determinarse si el hombre se vuelve calvo con el primer cabello arrancado, con el segundo o con el cuadragésimo, etcétera.

${ }^{58}$ Hay que decir que, en otros casos que no involucran cualidades de este tipo, el Sorites y el Calvo no corresponden estructuralmente a la Composición y la División. Más bien, el problema consiste en afirmar la imposibilidad de que los cambios en las partes (que son pequeños y numerosos) provoquen un cambio cualitativo en el todo, por el hecho de que dicho cambio no sería determinable analíticamente. No es casual que este tipo de argumentos se hayan utilizado para cuestionar la posibilidad de que el movimiento sea inteligible (cf. R. Muller, 1988, p. 140 y ss.). 
la totalidad no son pequeños, sino que están compuestos de cosas pequeñas (1307b30-39). ${ }^{59}$

El argumento sobre los pequeños gastos que llevan a dispensar una fortuna inadvertidamente corresponde a la estructura del Sorites, ${ }^{60} \mathrm{y}$ al momento de describir el argumento sofístico con el cual lo equipara, Aristóteles se refiere a la estructura que corresponde al tipo de argumento que aparece en $R h$. como Composición, pues lo define en términos de considerar que el todo es pequeño a causa de que sus partes son pequeñas. Nuevamente, la estructura que resulta común a ambos tipos de argumento aparente, y en última instancia la causa del argumento aparente, es la aplicación de un atributo de las partes al todo.

Veamos ahora los ejemplos de $R h$., II, 24 que ilustrarían el caso $b$ ), es decir, la Composición:

III) el argumento de Eutidemo, por ejemplo el saber que hay una trirreme en el Pireo, pues se conoce cada una de estas dos cosas (1401a28-29).

IV) lo que dijo Polícrates sobre Trasíbulo: que había eliminado a los treinta tiranos, pues compone (1401a34-36).

V) lo que se dice en el Orestes de Teodectes, pues se da a partir de una división: "es justo que si una mata a su esposo, muera ella también y que el hijo vengue a su padre" [...] pues en conjunto probablemente no sea justo (1401a36-1401b2).

Evidentemente, estos ejemplos resultan mucho menos claros e ilustrativos que los dos primeros. Por ello, en dos de los tres casos (III y IV), el análisis no podrá ir más allá de la mera conjetura.

Respecto al argumento III), A. Tovar (1953, nota 173 al libro II) y Q. Racionero (1990, nota 414 al libro II) señalan que se trataría de un argumento ampliamente conocido, ${ }^{61}$ dado que Aristóteles no se molesta en desarrollarlo. Según los autores, este argumento también es mencionado

${ }^{59}$ Sigo la traducción de M. Araujo y J. Marías.

${ }^{60}$ Cf. L. A. Dorion, 1995, p. 51.

${ }^{61}$ No se trata sin embargo del mismo ejemplo que se ofrece en el Eutidemo de Platón, como nota ya L. Spengel, 1867, ad 1401a26. Fortenbaugh, 2002, p. 10, advierte también que este ejemplo no es el mismo que se encuentra en el diálogo de Platón, y sugiere a raíz de esto la posibilidad de que hubiera algún tipo de colección de los sofismas de Eutidemo que estuviera en circulación en época de Aristóteles (e incluso hasta en tiempos de Galeno); lo mismo supone L. A. Dorion, 1995, p. 344. 
en $S E 20,177 b 12$, aunque allí era expuesto de otro modo y la causa del error derivaba de cómo se compone o se divide la frase misma; ${ }^{62}$ aquí, en cambio, se afirma que el error surge por ofrecer como fundamento de que se sabe que hay una trirreme en el Pireo el hecho de que se conoce cada una de estas dos cosas, o como dice Racionero "cada uno de los referentes de la frase" (loc. cit.).

Lo poco que se puede ver a partir de lo que Aristóteles expresa, es que este argumento parece constituir un caso paralelo, pero inverso de lo que sucedía en el I), atendiendo a la frase al final: "pues se conoce cada una de estas dos cosas" (y aquí habría que suponer "por separado"). Si en I), por el hecho de conocer un todo, se infería que las partes también eran conocidas, aquí se partiría inversamente del conocimiento de las partes por separado y se aduciría ello como fundamento para inferir el conocimiento del todo. Esto último podría consistir en el conocimiento del hecho de que hay trirremes en el Pireo, lo cual, siguiendo la estructura que se supone tendría el argumento, debería ser falso y resultar de la composición de otros dos conocimientos verdaderos. Pero no queda claro, sin embargo, cuáles son las dos cosas que se conocen por separado. ¿Habría que entender que del hecho de saber que hay trirremes, por un lado, y del hecho de conocer (o estar en) el Pireo, por el otro, se infiere que se sabe que hay trirremes en el Pireo? Por mi parte, no encuentro bases firmes para decidir si esta reconstrucción que arriesgo sería correcta o no.

En el caso IV) también resulta difícil detectar la falta del argumento y la fuente del error. Tampoco encuentro una fuente de esclarecimiento en los comentadores. La explicación del comentario anónimo a $R h$. indica que se afirma que Trasíbulo mató a un tirano en una oportunidad, a otro en otra, etcétera, llegando al número de treinta, y se concluye que mató a treinta tiranos de una vez. ${ }^{63}$ En tal caso, el paso ilegítimo

62 Dorion, 1995 , pp. 344-345, ofrece una explicación alternativa basándose en la reconstrucción de este argumento por parte de Ps. Alejandro. Según Dorion, el enunciado en cuestión no sería una propuesta sino la conclusión de un argumento en la cual se componen y se mezclan dos propuestas concedidas antes por separado. Esta explicación es similar a la que ofrece Spengel, 1867, ad 1401a26, quien ve también en $R h$., el argumento de $S E$, 20 en forma abreviada, y explica el error en sede dialéctica como la composición de dos sentencias verdaderas (que resultaría en una falsa, se supone). Es difícil, de todos modos, ir más allá de estas conjeturas aún en el texto de $S E$ en donde la falacia se expone con algo más de extensión.

${ }^{63}$ Anonymus, in Rh., 150.7-150.13. 
parece ser de "matar sucesivamente y uno por uno a treinta" a "matar de una vez a treinta", con lo cual habría que decir que la composición se daría entre los instantes o momentos en los cuales ocurre la acción (es decir, en las premisas cada acto de asesinato ocurriría en un momento separado, y en la conclusión se reúnen en un mismo instante todos los actos). Spengel (1867, ad 1401a33), por su parte, dice que la razón de que esta sea una falacia por composición es que se reúne a los treinta hombres, "los cuales, si fuera verdadera <la composición>, debieran separarse y mostrar que cada uno fue aniquilado por Trasíbulo". Con esto se insinúa que la conjunción sería falsa, pues Trasíbulo no habría matado a los treinta, sino sólo a algunos de ellos. El argumento partetodo funcionaría entonces del siguiente modo: de una o algunas partes se dice el haber sido asesinadas por Trasíbulo, y por lo tanto se concluye que del todo (los Treinta Tiranos) también puede mencionarse que ha sido aniquilado por Trasíbulo. En tal caso podría pensarse incluso que se trata de un fenómeno de metonimia. Piénsese por ejemplo en un caso análogo: en una batalla podría argumentarse que un soldado destruyó al ejército enemigo, por haber matado en realidad a su capitán, con lo cual el ejército acéfalo se encaminó a una derrota segura. En tal caso, lo que se dice de una parte del todo (el haber sido aniquilado por tal soldado), se traslada por metonimia al todo. Si esta explicación fuera correcta, permitiría entender, además, los comentarios de A. Tovar (1953, nota 174 al libro II) y Q. Racionero (1990, nota 416 al libro II). Ambos, a partir del testimonio de Quintiliano, mencionan que el sofista Polícrates habría pedido treinta recompensas para Trasíbulo por haber puesto fin al gobierno de los Treinta. En efecto si el matar a los Treinta se dice de Trasíbulo por metonimia, resulta falaz reclamar treinta recompensas, pues ese número no corresponde en realidad (o literalmente) a la cantidad de tiranos asesinados por él. De cualquier modo, como en el caso anterior, resulta difícil ir más allá de estas conjeturas.

El caso V) es el ejemplo más claro de este subgrupo y, a mi entender, el más parecido a los de $S E$. En efecto, el error parece surgir, en primera instancia, por entender la afirmación de corrido y no dividiéndola: esto es, entender "es justo que si una mata a su esposo, muera ella también y que el hijo vengue a su padre", en lugar de "es justo que si una mata a su esposo muera ella también", por un lado y "es justo que el hijo vengue a su padre", por el otro. Pero, en realidad, el problema no se resolvería meramente introduciendo pausas en la frase, sino más bien distinguiendo que 
cada uno de estos dos hechos es justo en sí mismo; pero si se combinan de modo que la que mata a su marido es también quien muere a manos de su hijo, quien así venga a su padre, entonces ya no es seguro que quepa a este hecho el calificativo "justo". En definitiva, es posible calificar a cada una de las acciones por separado como "justas"; pero si esas acciones se unen y se aplica a la combinación el calificativo de "justa" por el hecho de que cada una de esas acciones es en sí misma justa, entonces se comete una falacia. ${ }^{64}$

Puede pensarse por ejemplo en un orador que defienda el proceder de Orestes proponiendo por separado preguntas retóricas como "¿no es acaso justo que la que mata a su marido muera ella también?", y, por otro lado "¿no es acaso justo que el hijo vengue a su padre?” (ambas perfectamente aceptables así formuladas), y concluya a partir de lo anterior que la muerte de la Clitemnestra a manos de su hijo Orestes constituye algo justo. El error que se cometería en este caso parece también deberse a una falta de especificación del contexto o de todas las condiciones fácticas que rodean a la acción, puesto que al proponer "¿no es acaso justo que la que mata a su marido muera ella también?", el hipotético orador estaría omitiendo una circunstancia significativa, esto es, a manos de quién ha de morir ella (en este caso, nada menos que del hijo). Por ello agrega Aristóteles al final de este ejemplo que éste sería también un

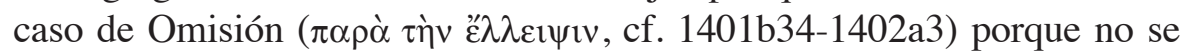

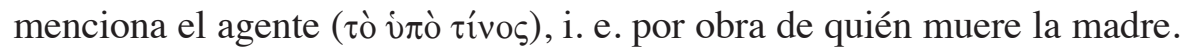

En definitiva, a partir del estudio y análisis detenido de los ejemplos de $R h$., II 24 y del realizado más arriba respecto de los ejemplos de $S E, 4$, pudo verse que la falacia de Composición y División en $S E$ y su homónima en $R h$. tienen en común muy poco más que el nombre. Las diferencias entre ambas resultan significativas, y no es posible, hasta donde veo, identificar una estructura común a la que ambas respondan o una misma causa que explique el error de ambos tipos de argumentos aparentes. A continuación procuraré referirme a ciertos aspectos de la retórica y de la dialéctica que permitirían dar cuenta, en alguna medida, de estas diferencias que hemos constatado.

${ }^{64}$ Cf. II, 23, 1397a28-1397b11, en donde se advierte sobre la posibilidad de cometer un paralogismo al calificar como "justo" a un hecho, una de cuyas partes resulta en realidad justa y la otra no tanto. Aquel análisis y los ejemplos que se aportan coincide en gran medida con la estructura del ejemplo que estamos considerando. 
En muchas ocasiones, ante la declaración inicial de $R h$. que establece que la retórica es la antistrofa o contraparte de la dialéctica, se tiende de modo preponderante a subrayar las semejanzas entre una y otra disciplina, y probablemente esto ocurre en gran medida porque el propio Aristóteles no se ocupa de señalar de manera explícita las diferencias entre ambas, sino que se concentra en enfatizar sus puntos en común. Con todo, la relación de antistrofía involucra al mismo tiempo una cierta oposición. ${ }^{65}$ En este apartado, señalaré algunos de los aspectos en los cuales la argumentación en sede retórica se aleja de la argumentación en sede dialéctica, con el objeto de encontrar cierto fundamento para los cambios que es posible constatar entre uno y otro tratamiento de lo falaz. Concretamente, entiendo que este fundamento puede encontrarse en las diferencias entre ambos modos de argumentación. En particular, me concentraré en aquellos aspectos que, según mi hipótesis, pueden explicar los cambios que hemos constatado en el tratamiento de las dos falacias estudiadas, la Composición y la División.

Las diferencias más importantes entre la argumentación dialéctica y retórica se pueden remitir al carácter privado de la primera y cívico de la segunda; al carácter dialógico de la argumentación dialéctica y al carácter eminentemente monológico de la argumentación retórica; 66 o al carácter de los medios mediante los cuales se intenta persuadir al

${ }^{65}$ Los sentidos de oposición y contrariedad o inversión son incluso los sentidos pri-

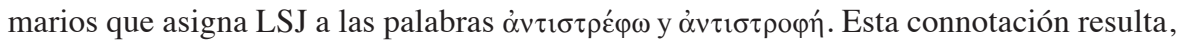
además, evidente si se tiene en cuenta, por un lado, que esta expresión se utilizaba originalmente en el ámbito teatral para indicar el movimiento del coro inverso al ocurrido en la estrofa y, por otro lado, que en ciertos usos matemáticos y lógicos por parte de Aristóteles, la palabra y/o sus derivados apuntan a una cierta inversión (cf. Einarson, 1936, p. 153). A los ejemplos aportados por Einarson, podemos agregar el de $P h$., VIII, 10,

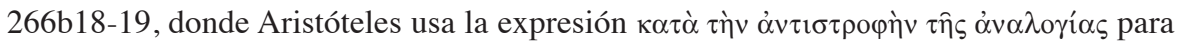
referirse a lo que hoy llamaríamos una proporción inversa entre el tiempo o duración del movimiento y la fuerza del mismo, i. e. cuanto más fuerza o potencia sea inherente a un objeto móvil, proporcionalmente menor será el tiempo en que cumpla el mismo movimiento, por lo cual esto sucede (traduciendo literalmente) "según la inversión de la analogía”. Cf. APr., I, 2, 25a6, 8, 10; Top., I, 5, 102a14.

${ }^{66} \mathrm{El}$ dialéctico procede por medio de preguntas y necesita ineludiblemente el asentimiento puntual de su interlocutor para construir su argumento, mientras que el retórico prescinde del asentimiento real del interlocutor para avanzar con su argumentación. 
auditorio/interlocutor: mientras que a este fin la dialéctica echa mano

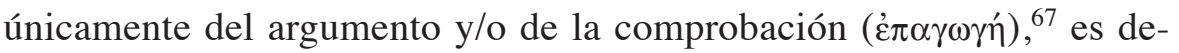
cir, de instrumentos de tipo intelectual, la retórica emplea, además, medios de orden no-intelectual, sino emocional para persuadir al auditorio, por ejemplo el éthos del orador o el recurso a suscitar las pasiones del público. Además de estas diferencias, que no analizaré a profundidad, existen otras dos en las que quiero detenerme: por una parte, la que se refiere al papel de la oralidad en uno y otro tipo de argumentación, y, por otra, la que se refiere al objeto sobre el cual versan los argumentos dialécticos y retóricos respectivamente.

Como más arriba he mencionado, existe la posibilidad de aplicar el estudio de los argumentos aparentes en sede dialéctica a la reflexión del científico o filósofo. La "discusión", en este caso, no sería conducida contra un interlocutor presente, sino que podría ser incluso contra otro filósofo, en cuyo caso esta suerte de discusión podría realizarse a partir de sus textos y por medio del lenguaje escrito. En retórica, en cambio, si se atiende a las funciones que la misma puede tener en sus tres versiones (deliberativa, forense y epidíctica), las cuales se refieren a la producción de persuasión en un jurado o auditorio, se trataría de discursos pronunciados de hecho frente a un grupo de personas, dado que el propósito de los mismos, cualquiera sea el género retórico de que se trate, sólo puede cumplirse cuando ellos son emitidos en una circunstancia concreta y puntual. Dicho de otro modo, el discurso retórico sólo puede cumplir la función que le es propia cuando es pronunciado frente a un auditorio y, por lo tanto, la argumentación retórica es eminentemente oral. ${ }^{68}$ En mi opinión, esta diferencia entre dialéctica y retórica, permite explicar

${ }^{67}$ Esta afirmación debería, por cierto, matizarse si se recuerda que en Top., VIII, 1 Aristóteles propone, además de las necesarias, la utilización de otro tipo de propuestas llamadas "paranecesarias" que, por ejemplo, incluyen (además de la comprobación y el prosilogismo) la ampliación y el adorno (cf. 155b22-23 y 157a6-13), cuya introducción responde al propósito de facilitar la aceptación de las necesarias por parte del interlocutor. Pero, de todos modos, entre estas estrategias paranecesarias no se encuentran, a mi entender, elementos equiparables al éthos y al páthos retóricos.

${ }^{68}$ En este punto, sin embargo, habría que conceder al menos una excepción para los discursos epidícticos, cuya función no estaría tan fuertemente limitada espacio-temporalmente (en este punto, los discursos epidícticos se acercarían en cierta medida a las obras de arte, cf. Burke, 1974); piénsese, por ejemplo, en el relato del Fedro, de Platón, en donde Fedro se dispone a leer un discurso epidíctico que Lisias ha pronunciado antes y que él tiene por escrito. De hecho, cuando Aristóteles distingue entre los estilos más apropiados 
el hecho de que el planteamiento dialéctico de las falacias de Composición y División no sea aplicado al campo retórico, sino que estas dos aparezcan en $R h$., II, 24 bajo una forma enteramente nueva ${ }^{69}$ En efecto, carece de sentido estudiar en sede retórica falacias que se apoyan en un elemento de indeterminación propio del lenguaje escrito, puesto que la argumentación retórica es eminentemente oral, y dicho elemento de indeterminación desaparece en el lenguaje oral.

En segundo lugar, digamos algo sobre el objeto sobre el que versan los argumentos dialécticos y retóricos respectivamente. El objeto de los primeros puede determinarse a partir de las cuestiones acerca de las que puede girar el problema dialéctico, ya que el mismo delimita aquello sobre lo que versarán ( $\pi \varepsilon \rho i ̀ \hat{\omega} v$ ) los argumentos (Top., 101b16). Aristóteles establece lo siguiente respecto al problema dialéctico: se trata de consideraciones que apuntan o bien al deseo y al rechazo (por ejemplo, si el placer es deseable o no, 104b7), o bien al conocimiento y la verdad (por ejemplo, si el mundo es eterno o no, 104b8), sea en sí mismas, sea porque contribuyen a esclarecer algún asunto perteneciente a uno de estos dos tipos (104b1-3, cfr. 104b8-10). Es decir, la dialéctica tendrá por objeto tanto cuestiones de tipo teórico, como de tipo práctico. Pero aun en el último caso, se trata de problemas de

para el discurso escrito y para el oral en $R h$., III, 12 asocia los discursos epidícticos con la práctica de la lectura (cf. 1414a18-19). Respecto a los otros dos géneros, sin embargo, sostengo que la función perlocucionaria que les es propia (acusar o defenderse/aconsejar) sólo puede cumplirse cuando estos son pronunciados en las circunstancias y la oportunidad que corresponden (i. e. frente a un juez o ante la asamblea, y en ocasión de un juicio o de un debate político, etc.). Las alusiones que pueden encontrarse en $R h$. a discursos escritos y que no son explícitamente focalizadas alrededor del género epidíctico (se trata de Rh., III, 1, 1404a18-19: III, 5, 1407b11-12), dejan en claro, sin embargo, que se trata de discursos escritos leídos en público, con lo cual sigue estando en primer plano la referencia a la oralidad como instancia de cumplimiento efectivo del discurso. La referencia al discurso escrito, entonces, en estos pasajes, marcaría simplemente la diferencia entre aquel que se pronuncia leyendo lo escrito de antemano y el que se pronuncia sin tal apoyo. Un dato no menor en relación con esta cuestión es el hecho de que Aristóteles se refiera tan frecuentemente (esp. en el libro III) al público destinatario de los discursos retóricos

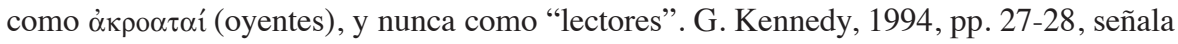
la práctica extendida en el s. IV de poner por escrito los discursos retóricos; pero en tal medida estos discursos eran considerados - subrayo - como material de estudio, es decir, cumplían otra función.

${ }^{69}$ Esta diferencia permitiría explicar también el hecho de que la falacia de acentuación de $S E$ no sea retomada en $R h$. 
orden general y no particular. ${ }^{70}$ La diferencia entre estos dos puede comprenderse al hilo de la diferencia entre filosofía práctica y prudencia ( $\varphi \rho o ́ v \eta \sigma ı \varsigma)$. Muy brevemente, aquella reflexiona en el plano de

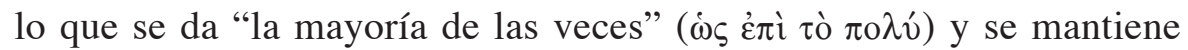
necesariamente en ese plano. La prudencia, en cambio, tiene por objeto además lo particular, aquello que es objeto de deliberación, ${ }^{71}$ que no es otra cosa que aquello que está en nuestro poder hacer. En la medida en que se dirige a la producción de acciones concretas, la prudencia requiere tanto un conocimiento de lo universal como de lo particular, pues la acción se da siempre en situaciones y circunstancias particulares a las que hay que hacer justicia. Como se verá en seguida, el objeto de la retórica y aquello que es objeto de deliberación (y por lo tanto de la prudencia) coinciden.

Volviendo a la dialéctica, las cuestiones discutidas por ella pueden tener tal grado de generalidad que muchas veces se le adjudican reflexiones en el plano del lenguaje mismo, en tanto y en cuanto Aristóteles, en sus investigaciones, procede muchas veces asumiendo que la estructura del lenguaje es capaz de reflejar la estructura de la realidad. ${ }^{72} \mathrm{Si}$ este planteo es correcto, permitiría entender el importante lugar que se da en $S E$ a las falacias de naturaleza lingüística, algo que contrasta con lo que ocurre en $R h .^{73}$

El tipo de cuestiones que pueden dar lugar a argumentos retóricos, y su contraste con aquello que da lugar a los argumentos dialécticos, es caracterizado por Aristóteles en $R h$. 1356b35-1357a1: allí nuestro filósofo sostiene que, mientras que la dialéctica argumenta $u$ ofrece pruebas a partir de aquellas cosas que necesitan explicación, la retórica argumenta

70 J. Brunschwig, 1984, p. 32.

${ }^{71}$ En más de un pasaje, la prudencia es definida como la capacidad de deliberar bien (cf. EN, VI, 5, 1140a25-28; Ib., 10, 1142b31-33).

72 Un claro y conocido ejemplo de esto es la búsqueda de los principios de los entes sujetos al devenir en $P h$., I, 7, la cual tiene como punto de partida el análisis de las formas lingüísticas en griego mediante las cuales usualmente se describen los procesos de cambio (véase la discusión ya clásica de W. Wieland, 1970, pp. 110-140).

${ }^{73}$ Respecto a la cercanía entre dialéctica y filosofía primera, cf. también Top., VIII, $1,155 \mathrm{~b} 7-8$, en donde se acercan las tareas del filósofo y del dialéctico, al menos en lo que excede a la situación concreta de diálogo, y Metaph., IV, 2, 1004b22-26, de donde se sigue que ambas versan acerca de las mismas cosas, es decir, tienen el mismo objeto. 
a partir de las cosas sobre las que ya es usual deliberar. ${ }^{74}$ La retórica, dice Aristóteles, versa sobre las cosas "acerca de las cuales deliberamos y no tenemos una técnica" (1357a2). En la dialéctica se trata de cuestiones de orden general y teórico, respecto de las cuales hace falta una explicación o un argumento. En cambio, en la retórica se trataría fundamentalmente de argumentar acerca de posibles cursos de acción, pues aquello sobre lo que se delibera (y aquello de lo que no hay $\tau \dot{\varepsilon} \chi v \eta)$ no son sino las acciones que uno realizará, ${ }^{75}$ toda vez que ellas resultan difíciles de llevar a la práctica, o no resulta claro qué es lo que hay que hacer. ${ }^{76}$ Esto implica que, por contraste con la dialéctica, la argumentación retórica involucra necesariamente, como su objeto propio, cuestiones de orden particular, especialmente aquellas que rodean a las acciones, y éstas mismas. ${ }^{77}$ Esta peculiaridad del objeto de la argumentación retórica, de hecho, era reconocida ya por Alejandro de Afrodisias: ${ }^{78}$ tales argumentos se refieren de un modo u otro a acciones, a las propiedades de éstas (incluyendo su valoración - sea moral o en vistas a lo conveniente-) y a las circunstancias que las rodean.

Si bien esta diferencia en el objeto de argumentación no puede explicar por sí misma las diferencias que hemos constatado en la falacia

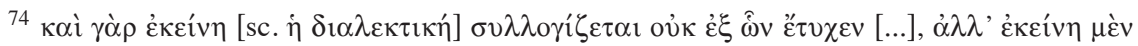

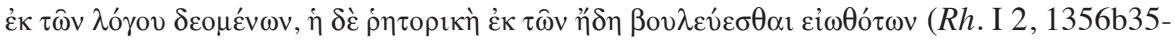
1357a1).

${ }^{75} E N$, III, 3, 1112a30-b9.

${ }^{76}$ Cf. EN, III, 3, 1112b8-9.

${ }^{77} R h .$, I, 2, 1357a22-27, Ib., II, 21, 1394a24-27; cf. Ib. 1360b7-14, 1363a20, 1363a31, 1399b30-35. En este sentido, además, J. Sprute, 1982, pp. 76-77, muestra que los entimemas a partir de lo probable (عiкós) en $R h$., a diferencia de los silogismos de los Analíticos, incluyen términos singulares. Esto no implica, por supuesto, que la retórica verse exclusivamente sobre lo particular y que no tenga en cuenta en modo alguno proposiciones generales.

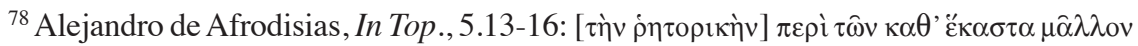

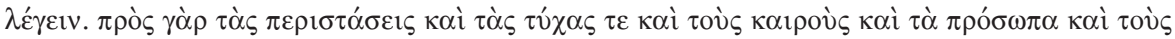

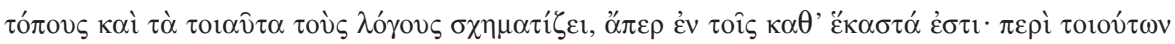

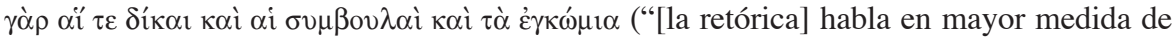
cosas particulares, pues elabora los discursos conforme a las circunstancias y el azar y las oportunidades y los lugares, $\mathrm{y}<\mathrm{en}$ general $>$ las cosas de este tipo, que son justamente particulares. En efecto, tanto los discursos judiciales como los discursos deliberativos y los encomios <versan> acerca de estas cosas" (la traducción es mía). Cf. en el mismo sentido, G. Most, 1994, pp. 172-73; G. Kennedy, 1994, p. 57; E. Krabbe, 2000, p. 211, entre otros. 
de Composición y División tanto en sede dialéctica como retórica, al menos ella permite advertir que la versión retórica de estas falacias, es decir, la que concierne a los argumentos parte-todo, se acomoda mucho mejor que la versión dialéctica al objeto de los argumentos retóricos. Los argumentos parte-todo, en efecto, giran fundamentalmente alrededor de la atribución de determinada propiedad a un objeto: el ser buenomalo, el ser conocido, el haber sido realizado por una persona (quien por ello merecerá honores), etcétera. Los ejemplos de $R h$., en general apuntan a propiedades que resultan interesantes o relevantes en el marco de la reflexión y de la argumentación referida a asuntos prácticos y están lejos de disquisiciones teóricas de altos niveles de generalidad, como son las propias de la dialéctica. ${ }^{79}$

\section{VI}

Hemos visto que, más allá de las diferencias que pueden constatarse a primera vista entre las falacias que integran la clasificación de $S E$ y las que integran la clasificación de $R h$., II, 24, hay, además, ciertos tipos de falacias que aparentemente se repiten en uno y otro tratado, y que podrían parecer aplicaciones retóricas de lo estudiado en dialéctica, pero en realidad se trata de casos que esconden bajo el mismo nombre diferentes estructuras falaces. La transformación de estos recursos homónimos, como he mostrado respecto de la Composición y la División (y podría ejemplificarse también en el caso del Accidente y la Falsa Causa),$^{80}$ es tan radical que resulta muy difícil sostener que se trata del mismo argumento falaz en uno y otro escrito.

En el caso de la Composición y la División, la distancia entre la versión dialéctica y la versión retórica de estos argumentos puede constatarse ya a partir del hecho de que este par de falacias ocupan en las $S E$ un lugar

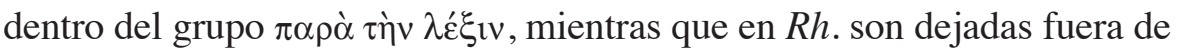

\footnotetext{
${ }^{79}$ Esto no implica, con todo, que las falacias de Composición y División en los argumentos parte-todo (i. e. en su versión retórica) sean exclusivamente retóricas. Evidentemente, desde el punto de vista estructural, la falacia puede darse en el ámbito dialéctico. Recuérdese al respecto el ejemplo del Eutidemo, de Platón retomado por Aristóteles en SE, 166a30-31 (cf. supra, nota 51). De todos modos resulta a mi entender significativo que Aristóteles omita el análisis de este caso en $S E$, y que, en cambio, plantee allí la falacia en términos totalmente diferentes.

${ }^{80}$ Para un análisis de las diferencias entre la falacia del Accidente en $S E$ y en $R h$. me permito remitir a G. Rossi, 2009.
} 
este grupo. En un caso (en $S E$ ) se trata de un fenómeno lingüístico que concierne a la ligazón o separación material de las palabras en una oración o propuesta; en cambio, en el otro caso $(R h$.) se pierde toda ligazón con el plano de la materialidad lingüística, y la causa de la falacia pasa a ser una concepción errónea de las relaciones objetivas entre un todo y sus partes. Por añadidura, el modo en que Aristóteles plantea esta falacia

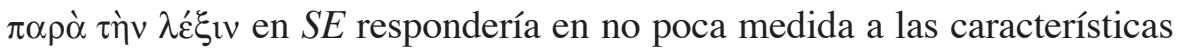
del lenguaje escrito en el s. IV a. C., peculiaridades que no compartimos hoy día y que serían uno de los motivos para que este argumento aparente no haya sido recogido en los estudios contemporáneos sobre falacias. Por el contrario, la versión que ha sobrevivido de éstas hasta los manuales de lógica contemporáneos es la de $R h$., II, $24 .{ }^{81}$ En sede retórica, estos entimemas aparentes se refieren a objetos extra-lingüísticos, fundamentalmente a acciones o a cuestiones relacionadas con la acción, como puede verse a partir de los ejemplos. Las dificultades en las relaciones parte-todo, que representan el contenido de la falacia de Composición y División en la $R h$., se refieren a la adjudicación de predicados o propiedades de objetos.

Este cambio en el contenido de las falacias homónimas, por último, no sería casual. Un examen de algunos rasgos distintivos de la argumentación en retórica y en dialéctica nos ha mostrado que el abandono de la versión dialéctica de la Composición y la División responde probablemente a la diferencia entre oralidad y escritura, predominantes, respectivamente, en la argumentación retórica y en la dialéctica, y que, además, la versión retórica de la Composición y la División parece ajustarse mejor al tipo de objeto sobre el que versan los argumentos retóricos que su homónima dialéctica.

\section{BIBLIOGRAFÍA}

Alejandro de Afrodisias, In Top = Wallies, M. (ed.), Alexandri Aphrodisiensis in Aristotelis Topicorum libros octo commentaria, CAG, vol. II 2-3, Berlín, 1891. Anonymus, in Rh. = Rabe, H. (ed.), Anonymi et Stephani in Artem Rhetoricam Commentarium, CAG., vol. XXI-2, Berlín, 1896.

Broyles, J. E., "The Fallacies of Composition and Division", Philosophy and Rhetoric, vol. 8, $\mathrm{N}^{\circ} 2,1975$, pp. 108-113.

${ }^{81}$ Cf., por ejemplo, I. Copi, 1972, pp. 109-113; H. Hansen y R. Pinto, 1995, p. 5 y 8. 
BRunschwig, J., "Aristotle on Arguments without Winners or Losers", Wissenschaftskolleg - Jahrbuch, 1984/85, pp. 31-40.

_, "Rhétorique et dialectique, Rhétorique et Topiques", en Furley, D. \& Nehamas, D., 1994, pp. 57-96.

_, J., "Préface", en L. A. Dorion, Aristote, Les réfutations sophistiques, trad. et notes par L. A. Dorion, Paris, 1995.

Burke, R., "Rhetoric, Dialectic, and Force", Philosophy and Rhetoric, vol. $7 \mathrm{~N}^{\circ}$ 3, 1974, pp. 154-165.

Cope, E. M. - Sandys, J.E. = The Rhetoric of Aristotle, with a Commentary by E. M. Cope. Revised and Edited by J.E. Sandys, Hildesheim-New York, 1970 (= Cambridge, 1877); vols. I-III.

Copi, I. M., Introducción a la Lógica, Buenos Aires, 1997 (orig. 1972).

Dorion, L. A., Aristote, Les réfutations sophistiques, trad. et notes par L. A. Dorion, Paris, 1995.

DÜRING, I., Aristóteles, Exposición e interpretación de su pensamiento, México, 1990 (orig. Heidelberg, 1966).

Ebbesen, S., Commentators and Commentaries on Aristotle's Sophistici Elenchi, Leiden, 1981.

EDLOw, R. B., Galen on Language and Ambiguity. An English Translation of Galen's "De Captionibus" with Introduction, Text and Commentary, Leiden, 1977.

EINARSON, B., "On certain Mathematical terms in Aristotle's Logic”, American Journal of Philology, LVII, 1936, pp. 33-59, 151-172.

Evans, J. D. G., “The codification of false refutations in Aristotle's De Sophisticis Elenchis", Proceedings of Cambridge Philosophy Society XXI, 1975, pp. 542-552.

Fortenbaugh, W., "Eudemus" Work On Expression", en I. Bodnár y W. Fortenbaugh (eds.) Eudemus of Rhodes (Rutgers University Studies in Classical Humanities, vol. XI), New Brunswick, 2002, pp. 59-83.

Furley, D., Nehamas, D. (eds.), Aristotle's Rhetoric. Philosophical Essays, Princeton, 1994.

Goodwin, W., Greek Grammar, London, 1924 (= 1894).

Hamblin, C. L., Fallacies, Vale Press, Virginia, 1998 (=1970).

Hansen, H. V., Pinto, R.C. (eds.), Fallacies: Classical and Contemporary Readings, Pennsylvania, 1995.

Hunger, H., Stegmüller, O. et al., Geschichte der Textüberlieferung der antiken und mittelalterlichen Literatur, Zürich, 1961, Bd. I.

JAEGer, W., Aristóteles, México, 1946 (orig. 1923).

Joseph, H. W., An Introduction to Logic, New Jersey 2000 (= Oxford 1916).

Kennedy, G., A New History of Classical Rhetoric, Princeton, 1994.

KenYon, F., Books and Readers in Ancient Greece and Rome, Oxford, 1951.

KrabBe, E., "Meeting in the House of Callias: Rhetoric and Dialectic", Argumentation 14, 2000, pp. 205-217.

Liddell, H. G., Scott, R., Jones, Greek-English Lexicon, Oxford 1992 (1940). 
M. Araujo y J. Marías, Aristóteles, Política, (ed. bilingüe) edición y trad. de Araujo, M. y Marías J., Introducción y notas de Marías, J., Centro de Estudios Constitucionales, Madrid, 1983 (=1970).

Most, G., "The Uses of endoxa: Philosophy and Rhetoric in the Rhetoric", en Furley, D. y Nehamas, D., 1994, pp. 167-190.

Muller, R., Les Mégariques, Fragments et témoignages, trad. et comm., Paris, 1985.

_, Introduction à la pensée des Mégariques, Paris, 1988.

Ps. Alejandro, in $S E=$ Wallies, M. (ed.) (1891), Alexandri quod fertur in aristotelis Sophisticos Elenchos Commentarium, CAG, vol. II 3, Berlin, 1891.

Racionero, Q., Aristoteles, Retórica, introducción, traducción y notas de Q. Racionero, Madrid, 1990.

RAPHAEL, S., "Rhetoric, Dialectic, and syllogistic argument: Aristotle"s position in Rhetoric I-II", Phronesis 19, 1974, pp. 153-167.

Schiaparelli, A., "L"influenza della Retorica di Aristotele in età imperiale: l"importanza di essere chiaramente ambigui", Méthexis XII, 1999, pp. 53-75.

Spengel, L., Aristotelis, Ars Rhetorica, cum adnotatione Leonardi Spengel, Lipsiae, 1867.

Sprague, R. K., Plato's Use of Fallacy, London, 1962.

SPRUTE, J., Die Enthymemtheorie der aristotelischen Rhetorik, Göttingen, 1982.

Tovar, A., Aristóteles, Retórica, (ed. bilingüe) edición y trad. de Tovar, A., Centro de Estudios Políticos y Constitucionales, Madrid, 1999 (=1953).

Turner, E., Greek Papyri. An Introduction, Princeton, 1968.

Wieland, W., Die aristotelische Physik, Göttingen, 1970.

Woods, J., "Files of Fallacies: Aristotle (384-322 B.C.)", Argumentation 13, 1999, pp. 203-220. 